\title{
Total OH Reactivity of Emissions from Humans: In Situ Measurement and Budget Analysis
}

Nijing Wang,* Nora Zannoni, Lisa Ernle, Gabriel Bekö, Pawel Wargocki, Mengze Li, Charles J. Weschler, and Jonathan Williams

Cite This: Environ. Sci. Technol. 2021, 55, 149-159

Read Online

ABSTRACT: Humans are a potent, mobile source of various volatile organic compounds (VOCs) in indoor environments. Such direct anthropogenic emissions are gaining importance, as those from furnishings and building materials have become better regulated and energy efficient homes may reduce ventilation. While previous studies have characterized human emissions in indoor environments, the question remains whether VOCs remain unidentified by current measuring techniques. In this study conducted in a climate chamber occupied by four people, the total $\mathrm{OH}$ reactivity of air was quantified, together with multiple VOCs measured by proton transfer reaction time-of-flight mass spectrometry (PTR-ToF-MS) and fast gas chromatography-mass spectrometry (fast-GC-MS). Whole-body, breath, and dermal emissions were assessed. The comparison of

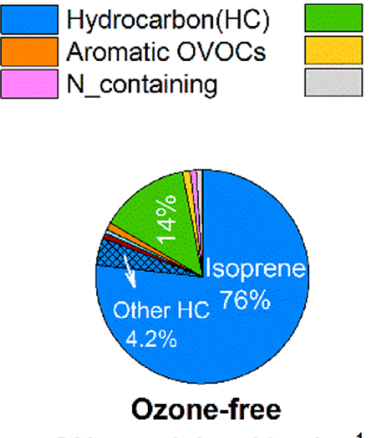

OH reactivity: $16 \pm 2 \mathrm{~s}^{-1}$

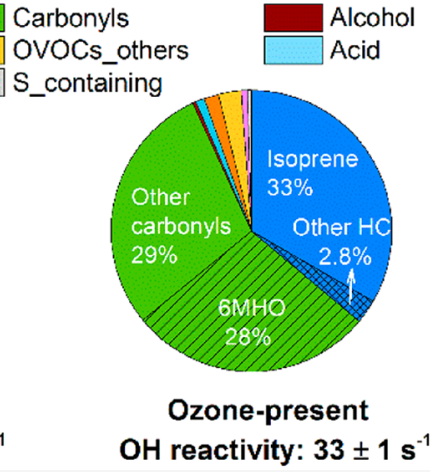
directly measured $\mathrm{OH}$ reactivity and that of the summed reactivity of individually measured species revealed no significant shortfall. Ozone exposure (37 ppb) was found to have little influence on breath $\mathrm{OH}$ reactivity but enhanced dermal $\mathrm{OH}$ reactivity significantly. Without ozone, the whole-body $\mathrm{OH}$ reactivity was dominated by breath emissions, mostly isoprene (76\%). With ozone present, $\mathrm{OH}$ reactivity nearly doubled, with the increase being mainly caused by dermal emissions of mostly carbonyl compounds (57\%). No significant difference in total OH reactivity was observed for different age groups (teenagers/young adults/seniors) without ozone. With ozone present, the total OH reactivity decreased slightly with increasing age.

\section{INTRODUCTION}

People spend on average $80 \% \sim 90 \%$ of their time indoors and more than $60 \%$ in their home residence. ${ }^{1-5}$ Therefore, the indoor air quality plays an important role in human health as people are exposed to numerous chemical compounds for long periods within their indoor home environment. ${ }^{6,7}$ The degree of exposure is even higher while movement restrictions are in force, e.g., associated with pandemic outbreaks.

For the last 20-30 years, the main focus of indoor research has been on building-related emissions such as building materials, furnishings, and paints; numerous volatile organic compounds (VOCs) have been measured from such sources. ${ }^{8-13}$ However, with improved manufacturing techniques, these emissions gradually decreased, increasing the relative importance of emissions from occupants themselves.

Humans are a potent, mobile source of chemicals in indoor environments. Several hundred bioeffluent VOCs are known to be emitted via breath and skin. ${ }^{14}$ In the presence of oxidants such as ozone or the hydroxyl radical $(\mathrm{OH})$, oxidation products can be formed. ${ }^{15-19}$ Besides, indoor $\mathrm{OH}$ concentrations have been measured and modeled in several studies that indicate the common occurrence of levels on the order of
$10^{5}$ molecules $\mathrm{cm}^{-3} \cdot{ }^{20-24}$ Despite the application of advanced measurement technology in recent studies, the following question remains: Are we measuring all of the $\mathrm{OH}$ reactive species related to indoor human emissions? The question can be addressed by measurements of total $\mathrm{OH}$ reactivity, which provides a direct measurement of the total loss rate of $\mathrm{OH}$ radicals in the air. When this value is compared to the sum of the $\mathrm{OH}$ reactivity contributed by the individually measured species, any difference will indicate that the characterization of species has been insufficient. Studies made outdoors have revealed significant differences between measured and calculated reactivity. ${ }^{25-28}$ The missing fraction in comparison to known species gives important insights into possible unknown primary emission sources and secondary products.

Received: June 27, 2020

Revised: October 28, 2020

Accepted: November 24, 2020

Published: December 9, 2020

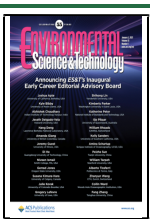


Table 1. Experimental Conditions and Information

\begin{tabular}{|c|c|c|c|c|}
\hline $\begin{array}{l}\text { experiment number } \\
\text { (replicate) }\end{array}$ & experiment type & $\begin{array}{c}\text { temperature }\left({ }^{\circ} \mathrm{C}\right) \\
\text { (replicate) }\end{array}$ & relative humidity (\%) (replicate) & age \\
\hline 1 & whole-body: young adult (group A1) & $26.2-30.3$ & $31-35$ & mean: $25(19-30)$ \\
\hline $6(21)$ & whole-body: young adult (group A2) & $\begin{array}{l}23.7-27.5 \\
(23.3-27.7)\end{array}$ & $\begin{array}{l}16-23 \\
(17-25)\end{array}$ & \\
\hline 10 & whole-body: young adult (group A3) & $25.3-28.8$ & $28-31$ & \\
\hline $18(26)$ & whole-body: teenager (group T4) & $\begin{array}{l}24.6-28.4 \\
(25.8-30.0)\end{array}$ & $\begin{array}{l}29-37 \\
(30-36)\end{array}$ & $\begin{array}{l}\text { mean: } 13.8 \\
(13-15)\end{array}$ \\
\hline $16(25)$ & whole-body: senior (group S5) & $\begin{array}{l}25.3-29.7 \\
(25.4-29.0)\end{array}$ & $\begin{array}{l}24-30 \\
(24-28)\end{array}$ & $\begin{array}{l}\text { mean: } 70.5 \\
(68-72)\end{array}$ \\
\hline 12 & breath: young adult (group A3) & $32.2-32.6$ & $56-62$ & \\
\hline 13 & skin: young adult (group A3) & $26.3-29.9$ & $24-28$ & \\
\hline
\end{tabular}

${ }^{a}$ Experiment numbers are identical to those in Bekö et al. ${ }^{42}$ Numbers in parentheses refer to replicate measurements.

The $\mathrm{OH}$ reactivity in this study is determined using the comparative reactivity method (CRM), ${ }^{29}$ which has been applied in various outdoor locations worldwide from megacities to rainforests. ${ }^{25,26,30-32}$ A recent intercomparison of $\mathrm{OH}$ reactivity methods has shown that the CRM method accurately measures $\mathrm{OH}$ reactivity, ${ }^{33}$ especially under high $\mathrm{OH}$ reactivity conditions. Therefore, indoor environments, where high $\mathrm{OH}$ reactivity can be expected, present a good application for this method.

Several studies have characterized VOCs from people in various real world indoor environments including aircraft cabins, offices, classrooms, movie theaters, and museums. ${ }^{34-39}$ These results inevitably represent emissions from people combined with inputs from clothing, detergents, fragrances, furnishings, and furniture. While limited indoor studies have considered the $\mathrm{OH}$ reactivity contributions of measured indoor VOCs, ${ }^{40}$ to our knowledge, none to date have compiled a budget based on a direct total $\mathrm{OH}$ reactivity measurements. Therefore, measuring the total $\mathrm{OH}$ reactivity and VOCs exclusively from human emissions is needed to answer whether current indoor air trace gas measurements provide a complete chemical characterization of human emissions from different sources (breath and skin), including their variations under different well-controlled conditions. Of special interest is the total $\mathrm{OH}$ reactivity of human emissions in the presence of ozone, one of the most important indoor oxidants. ${ }^{41}$

This study is a part of the Indoor Chemical Human Emissions and Reactivity (ICHEAR) project, which aims to comprehensively characterize the human contribution to indoor air chemistry. The goals of this work are to (1) define the $\mathrm{OH}$ reactivity of indoor air resulting from whole-body human emissions, as well as isolated breath and dermal emissions; (2) identify if any missing reactivity exists and the fractional composition of the $\mathrm{OH}$ reactivity; (3) examine the effect of ozone; (4) examine the effect of human age.

\section{METHODS}

2.1. Chamber Experiment Setup. Two $22.5 \mathrm{~m}^{3}$ stainlesssteel climate chambers at the Technical University of Denmark were used for all experiments. The stainless-steel chamber minimizes the influence of surface effects and emissions from furnishings and decorative materials. Detailed information about the experimental design and the instrumental setup are given by Bekö et al. ${ }^{42}$ In brief, precleaned chambers were ventilated with filtered outdoor air at an air change rate (ACR) of $3.2 \pm 0.11 \mathrm{~h}^{-1}$ (mean value calculated from measurement of $\mathrm{CO}_{2}$ decay as well as Freon134a tracer gas, details in Bekö et $\mathrm{al}^{42}$ ). The temperature and the relative humidity of the chambers were controlled and monitored. For the duration of an experiment, four volunteers were asked to stay inside the chamber wearing standardized long-sleeve shirts, pants, and calf socks ("long" clothing) or t-shirts, shorts, and ankle socks ("short" clothing), which were prewashed with fragrance-free detergent and tumble-dried after purchase. In the subset of experiments designed to characterize the impact of ozone, ozone was generated using a Jelight $600 \mathrm{UV}$ ozone generator and introduced into the chamber supply air to achieve the targeted mixing ratio of $\sim 100 \mathrm{ppb}$ in an unoccupied chamber. With four people present, the steady-state ozone level fell to 37 ppb. The ozone loss due to the chamber surface without people present was relatively small $(\sim 5 \%){ }^{42}$ The experiments were performed with three groups of young adults, a teenage group, and a senior group.

In this study (Table 1), the identical experiments with the five groups (benchmark experiments, Experiments 1, 6, 10, 16, and 18) and their replicates (Experiments 21, 25, and 26) were selected to determine the total $\mathrm{OH}$ reactivity of human wholebody emissions under ozone-free and ozone-present conditions, as well as the potential variation of total $\mathrm{OH}$ reactivity with age. For each benchmark experiment, volunteers wearing long clothing stayed in the chamber for $\sim 3 \mathrm{~h}$ in the morning. Then, after a short lunch break (10-15 min), volunteers reentered the chamber for the afternoon period $(\sim 2.5 \mathrm{~h})$. Ozone was introduced approximately $10 \mathrm{~min}$ after they re-entered the chamber. In addition to the benchmark conditions, additional experiments were performed in order to examine breath and skin emissions separately. This was achieved by using two identical chambers and asking the volunteers to breathe through a mask (Sperian ValuAir Plus $6100 \mathrm{~V}$ series RP155). They inhaled air from the chamber in which they sat and exhaled air into the second chamber. As the main inlet for all measurement instruments was fixed in the primary chamber, where the whole-body experiments were performed, the skinonly Experiment 13 was performed by asking the volunteers to sit in the primary chamber, while the breath-only Experiment 12 was achieved by having the volunteers sit in the second chamber. Ozone was always introduced into the primary chamber.

2.2. Total $\mathrm{OH}$ Reactivity Measurement and Data Analysis. A common inlet for all instruments (i.d. $=12.7 \mathrm{~mm}$, length $5 \mathrm{~m}$, fluorinated ethylene propylene tubing) was attached inside the chamber air outlet, to draw air exiting the chamber to instruments at $7 \mathrm{~L} \mathrm{~min}^{-1}$. The inlet was manually controlled via a three-way valve (Galtek Solenoid 
Valves, Entegris, Inc.) to allow for switching between the chamber's supply air and exhaust airstreams. A subflow (i.d. =

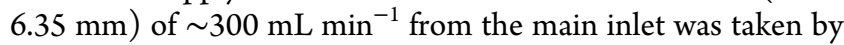
the CRM system, which mainly consists of a glass reactor and a detector (a proton transfer quadrupole mass spectrometer, PTR-QMS produced by Ionicon Analytik).

The principle of the CRM is to monitor the concentration variations of a reference molecule with a known $\mathrm{OH}$ rate constant (pyrrole in this study, Westfalen AG) when it reacts with $\mathrm{OH}$ radicals alone or when mixed with ambient air in a glass reactor. ${ }^{29}$ The $\mathrm{OH}$ radicals were generated by flushing humidified nitrogen (6.0 grade, Westfalen AG) through a $\mathrm{Hg}-$ Ar UV lamp (LOT Quantum Design). The pyrrole variations were detected by the PTR-QMS at $\mathrm{m} / z 68$ operated under drift pressure at $2.2 \mathrm{mbar}$, temperature at $60{ }^{\circ} \mathrm{C}$, and voltage at $600 \mathrm{~V}(\mathrm{E} / \mathrm{N}=137 \mathrm{Td}) .{ }^{29}$ The detailed CRM operating procedures can be found in the Supporting Information (SI). Due to a failure of the drift tube temperature control in PTRQMS during the experiments with the senior group (Experiments 16 and 25), the measured total $\mathrm{OH}$ reactivity data for those particular experiments are not available.

The measured $\mathrm{OH}$ reactivity was corrected for possible interferences (humidity and nonpseudo-first-order condition) according to previous studies. ${ }^{29,33,43}$ Interference from NOx ( $\mathrm{NO}$ and $\mathrm{NO}_{2}$ ) was deemed negligible due to their low mixing ratios (mostly of time near and below the limits of detection, 1 $\mathrm{ppb}$ ). The interferences are described in greater detail in the SI. The limit of detection (LOD, $3 \sigma$ ) during the campaign was $5 \mathrm{~s}^{-1}$. The total uncertainty of the $\mathrm{OH}$ reactivity data was $\sim 50 \%$ (median and mean), with the precision error ranging from $12 \%-54 \%$ for the experiments included in this study. The detailed calculations of total uncertainty and precision can be found in the SI.

2.3. VOCs and Other Trace Gas Measurements. A proton transfer time-of-flight mass spectrometer (PTR-ToFMS 8000, Ionicon Analytik) was used to measure VOCs in the chamber. The instrument sampled the same main inlet air as the CRM instrument by taking another substream of $\sim 100 \mathrm{~mL}$ $\min ^{-1}$ (i.d. $=3.18 \mathrm{~mm}$ ). The PTR-ToF-MS was operated under standard conditions (same as PTR-QMS used in CRM) using protonated water $\left(\mathrm{H}_{3} \mathrm{O}^{+}\right)$as the primary ions. Compounds with a proton affinity higher than water were detected at their protonated mass $\left(\mathrm{MH}^{+}\right){ }^{44}$ Four-point calibrations were performed throughout the campaign using a standard gas mixture containing the 14 compounds listed in Table S2 (Apel-Riemer Environmental Inc.). The time resolution of the measurement was $20 \mathrm{~s}$ with a mass resolution of 4000 at mass $96 \mathrm{amu}$. The LOD $(3 \sigma)$ for the VOCs measured by PTR-ToF-MS ranged from 7 to $171 \mathrm{ppt}$ for compounds calibrated with the gas standard. For other detected masses, empirical formulas were assigned and the mixing ratios of those masses were calculated using the theoretical calculation method assuming a constant proton transfer rate coefficient, with an associated uncertainty of $\sim 50 \%$. ${ }^{45}$ Here, an exception was made for 6-methyl-5-hepten2-one (6MHO), which is a main product of squalene ozonolysis. ${ }^{37}$ The mixing ratio was corrected to the reported proton transfer rate coefficient. ${ }^{46}$ Due to high abundance of $6 \mathrm{MHO}$ (above $4 \mathrm{ppb}$ when ozone was present reported in Bekö et al. $^{42}$ ) and its measured fast reaction rate with $\mathrm{OH}$ radicals $\left(1.57 \times 10^{-10} \mathrm{~cm}^{3}\right.$ molecules ${ }^{-1} \mathrm{~s}^{-1}$, see Table S2), the uncertainty of calculated reactivity (see Section 2.4) for
$6 \mathrm{MHO}$ as well as the total reactivity would be overestimated if no correction was applied.

The mixing ratios of isoprene and propanal (i.e., propionaldehyde) were taken from a custom-made fast-gas chromatograph-mass spectrometer (fast-GC-MS) deployed for the campaign with a LOD $<25 \mathrm{ppt}$ and a total uncertainty $<10 \%$. This is because the PTR-Tof-MS was found to have interferences for isoprene since $\mathrm{C}_{5} \mathrm{H}_{8} \mathrm{H}^{+}(\mathrm{m} / z$ 69.070) could also result from fragmentation of aldehydes with a carbon number larger than four ${ }^{47}$ and the instrument could not distinguish propanal and acetone. The fast-GC-MS was operated in selected ion monitoring (SIM) mode to measure certain VOCs at a time resolution of $3 \mathrm{~min}$. Details of the operation method were described by Bourtsoukidis et al. ${ }^{48}$

Ammonia $\left(\mathrm{NH}_{3}\right)$ was measured by a manufacturercalibrated cavity ring-down spectrometer (Picarro G2103). A detailed description of the $\mathrm{NH}_{3}$ measurement was reported by $\mathrm{Li}$ et al. $^{49}$ Ozone was measured by an ozone monitor (Model 205, 2B Technologies). $\mathrm{NO}$ and $\mathrm{NO}_{2}$ were continuously monitored by a chemiluminescence $\mathrm{NO} / \mathrm{NOx}$ analyzer (ECO PHYSICS, model CLD $700 \mathrm{AL}$ ).

2.4. Calculated $\mathrm{OH}$ Reactivity. In order to compare the directly measured total $\mathrm{OH}$ reactivity with the $\mathrm{OH}$ reactivity from all measured species, the total "calculated $\mathrm{OH}$ reactivity" was obtained on the basis of the measured trace gas concentrations using the following equation:

$$
R=\sum k_{\mathrm{X}_{\mathrm{i}}+\mathrm{OH}}\left[X_{\mathrm{i}}\right]
$$

where $\left[X_{\mathrm{i}}\right]$ is the concentration of trace gas species $i$ and $k_{\mathrm{X}_{\mathrm{i}}+\mathrm{OH}}$ refers to the rate constant $\left(\mathrm{cm}^{3}\right.$ molecule $\left.\mathrm{e}^{-1} \mathrm{~s}^{-1}\right)$ of species $i$ reacting with the $\mathrm{OH}$ radical. In total, 78 species with assigned empirical formulas and chemical structures were considered in the calculation; these compounds were detected above the LODs most of the time and are related to human emissions (higher mixing ratios detected with volunteers inside the chamber in comparison with the empty chamber). These species were grouped into hydrocarbons (HC), oxygenated volatile organic compounds (OVOCs), nitrogen containing compounds, and sulfur containing compounds. OVOCs were further divided into five subgroups: alcohols, acids, oxygenated aromatics, carbonyls, and others. The list of species with corresponding $k_{\mathrm{X}_{\mathrm{i}}+\mathrm{OH}}$ values taken from the published literature is shown in Table S2. As some measured PTR-ToF-MS masses can be isomeric compounds, an averaged $k_{\mathrm{X}_{\mathrm{+}} \mathrm{OH}}$ was derived for isomeric compounds with known rate constants (Table S2). However, for some isomeric carbonyls, specific compounds were assigned to the formula according to Wisthaler and Weschler ${ }^{37}$ who reported carbonyl products from human skin lipid reaction with ozone. For some compounds whose rate constants with the $\mathrm{OH}$ radical are unknown, rate constants for compounds with similar chemical structure were used. The uncertainty of the $k_{\mathrm{X}_{\mathrm{i}}+\mathrm{OH}}$ for standard-calibrated compounds and specifically assigned compounds was estimated to be $\sim 10 \%$, while for the averaged $k_{\mathrm{X}_{\mathrm{i}}+\mathrm{OH}}$ derived from isomeric compounds, a large uncertainty (100\%) was estimated. ${ }^{30}$ The uncertainty of calculated reactivity for each species is a propagation of uncertainties from the mixing ratio and the $k_{\mathrm{X}_{\mathrm{i}}+\mathrm{OH}}$. Therefore, the total uncertainty of the total calculated $\mathrm{OH}$ reactivity is highly dependent on the reactivity fraction of the species having less uncertainty (i.e., standard-calibrated 


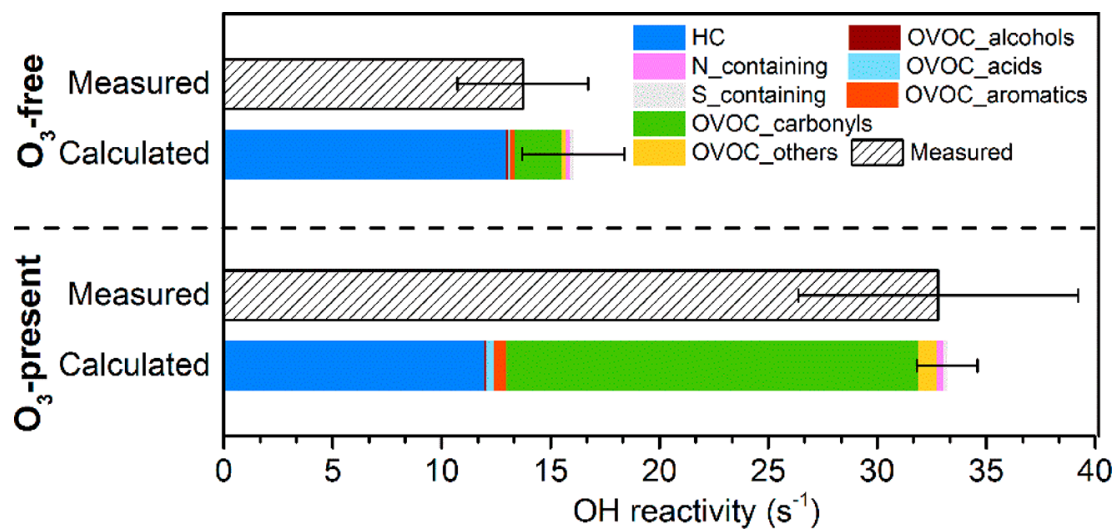

Figure 1. Calculated and measured $\mathrm{OH}$ reactivity of adult whole-body emissions under ozone-free and ozone-present conditions. Error bars represent the standard deviation derived from the data of four benchmark experiments (Experiments 1, 6, 10, and 21).

Table 2. Top 10 Species Contributing to the Calculated OH Reactivity of Adult Whole-Body Emissions (average levels and standard deviations of Experiments 1, 6, 10, and 21) under Ozone-Free and Ozone-Present Conditions

\begin{tabular}{|c|c|c|c|c|}
\hline & $\operatorname{mass}\left(\mathrm{H}^{+}\right)$ & compounds & $\mathrm{OH}$ reactivity $\pm \mathrm{SD}\left(\mathrm{s}^{-1}\right)$ & fraction $\pm \mathrm{SD} \%$ \\
\hline \multirow[t]{12}{*}{ ozone-free } & $a$ & isoprene & $12 \pm 2.4$ & $76 \pm 3.8$ \\
\hline & 137.132 & limonene & $0.6 \pm 0.1$ & $3.6 \pm 1.0$ \\
\hline & 127.112 & $6 \mathrm{MHO}$ & $0.4 \pm 0.1$ & $2.6 \pm 1.3$ \\
\hline & 45.034 & acetaldehyde & $0.3 \pm 0.2$ & $2.0 \pm 0.9$ \\
\hline & $b$ & ammonia & $0.2 \pm 0.1$ & $1.2 \pm 0.5$ \\
\hline & 195.186 & geranyl acetone & $0.2 \pm 0.1$ & $1.1 \pm 0.6$ \\
\hline & 87.044 & 1,4-butanedial & $0.1 \pm 0.0$ & $0.9 \pm 0.1$ \\
\hline & 33.034 & methanol & $0.1 \pm 0.0$ & $0.8 \pm 0.3$ \\
\hline & 91.057 & $\mathrm{C}_{4} \mathrm{H}_{10} \mathrm{~S}$ & $0.1 \pm 0.1$ & $0.7 \pm 0.5$ \\
\hline & 71.049 & $\mathrm{C}_{4} \mathrm{H}_{6} \mathrm{O}$ & $0.1 \pm 0.0$ & $0.7 \pm 0.2$ \\
\hline & sum of top 10 species & & $14 \pm 2.4$ & $90 \pm 1.6$ \\
\hline & sum of all species & & $16 \pm 2.3$ & \\
\hline \multirow[t]{12}{*}{ ozone-present } & $a$ & isoprene & $11.0 \pm 1.2$ & $33 \pm 3.8$ \\
\hline & 127.112 & $6 \mathrm{MHO}$ & $9.3 \pm 1.1$ & $28 \pm 1.2$ \\
\hline & 101.096 & 4OPA & $1.9 \pm 0.2$ & $5.8 \pm 0.1$ \\
\hline & 143.143 & nonanal & $1.2 \pm 0.1$ & $3.5 \pm 0.1$ \\
\hline & 87.044 & 1,4-butanedial & $0.8 \pm 0.1$ & $2.5 \pm 0.1$ \\
\hline & 45.034 & acetaldehyde & $0.8 \pm 0.2$ & $2.5 \pm 0.8$ \\
\hline & 137.132 & limonene & $0.7 \pm 0.1$ & $2.2 \pm 1.0$ \\
\hline & 141.127 & nonenal & $0.7 \pm 0.1$ & $2.0 \pm 0.1$ \\
\hline & $a$ & propanal & $0.6 \pm 0.1$ & $1.8 \pm 0.0$ \\
\hline & 195.186 & geranyl acetone & $0.4 \pm 0.1$ & $1.3 \pm 0.5$ \\
\hline & sum of top 10 species & & $27 \pm 1.4$ & $82 \pm 0.8$ \\
\hline & sum of all species & & $33 \pm 1.4$ & \\
\hline
\end{tabular}

${ }^{a}$ Isoprene and propanal data were obtained from fast-GC-MS. ${ }^{b}$ Ammonia data was obtained from a cavity ring-down spectrometer (Picarro G2103).

compounds), with a mean and median uncertainty of $29 \%$ for the experiments in this study.

Data from each experiment during the steady-state condition before volunteers exited the chamber were selected and averaged for both measured and calculated $\mathrm{OH}$ reactivity. A steady state was assumed when the relative change of the calculated reactivity was small at the end of each experiment (see details in the SI), meaning the total production rate of reactive species due to human occupants was equivalent to their total loss rate, which included air exchange and deposition to chamber surfaces. The data during the steadystate period reported in this study were background corrected by subtracting the measured mean value in the empty chamber before volunteers entered.

\section{RESULTS AND DISCUSSION}

3.1. Total $\mathrm{OH}$ Reactivity of Whole-Body Emissions. Four benchmark experiments $(1,6,21$, and 10) involving three different groups of young adult volunteers were selected to represent the whole-body emission from adults, with the mean levels of measured and calculated $\mathrm{OH}$ reactivity shown in Figure 1. In general, the $\mathrm{OH}$ reactivity due to occupancy by four adults was $14 \pm 3 \mathrm{~s}^{-1}$ under the ozone-free condition and increased to $33 \pm 6 \mathrm{~s}^{-1}$ with ozone present. There was good agreement with the calculated $\mathrm{OH}$ reactivity of $16 \pm 2$ and 33 $\pm 1 \mathrm{~s}^{-1}$ under ozone-free and ozone-present conditions, respectively. In other words, the calculated $\mathrm{OH}$ reactivity matched well with the measurements, considering the associated uncertainty (Figure S1). The $\mathrm{OH}$ reactivities of whole-body emissions from four people in the ventilated 
Table 3. Per-Person OH Reactivity from Human Emissions in Various Studies

\begin{tabular}{|c|c|c|c|c|c|}
\hline indoor environments & $\begin{array}{l}\text { OH reactivity per person before } \\
\text { adjustment }\left(\mathrm{s}^{-1} \mathrm{p}^{-1}\right)\end{array}$ & indoor volume $\left(\mathrm{m}^{3}\right)$ & outdoor ACR $\left(\mathrm{h}^{-1}\right)$ & $\begin{array}{l}\text { indoor ozone } \\
\text { level (ppb) }\end{array}$ & $\begin{array}{l}\text { OH reactivity per person after } \\
\text { adjustment }\left(\mathrm{s}^{-1} \mathrm{p}^{-1}\right)\end{array}$ \\
\hline \multicolumn{6}{|c|}{ present study } \\
\hline chamber (ozone-free) & 4.0 & 22.5 & 3.2 & $<1$ & 4.0 \\
\hline chamber (ozone-present) & 8.3 & 22.5 & 3.2 & 37 & 8.3 \\
\hline \multicolumn{6}{|c|}{ other studies } \\
\hline classroom (Tang et al. ${ }^{36}$ ) & $0.12^{a}$ & 670 & 5 & not reported & 5.4 \\
\hline cinema (Stönner et al. ${ }^{35}$ ) & $0.055^{a}$ & 1300 & 5 & low & 5.0 \\
\hline gallery room (high-occupancy & $0.080^{b}$ & 6000 & 0.8 & 5 & 5.3 \\
\hline
\end{tabular}

${ }^{a} \mathrm{OH}$ reactivity per person before adjustment was estimated using reported VOCs emission rates, details shown in the Supporting Information. ${ }^{b} \mathrm{OH}$ reactivity per person before adjustment was estimated on the basis of reported $\mathrm{OH}$ reactivity and occupancy number, details shown in the Supporting Information.

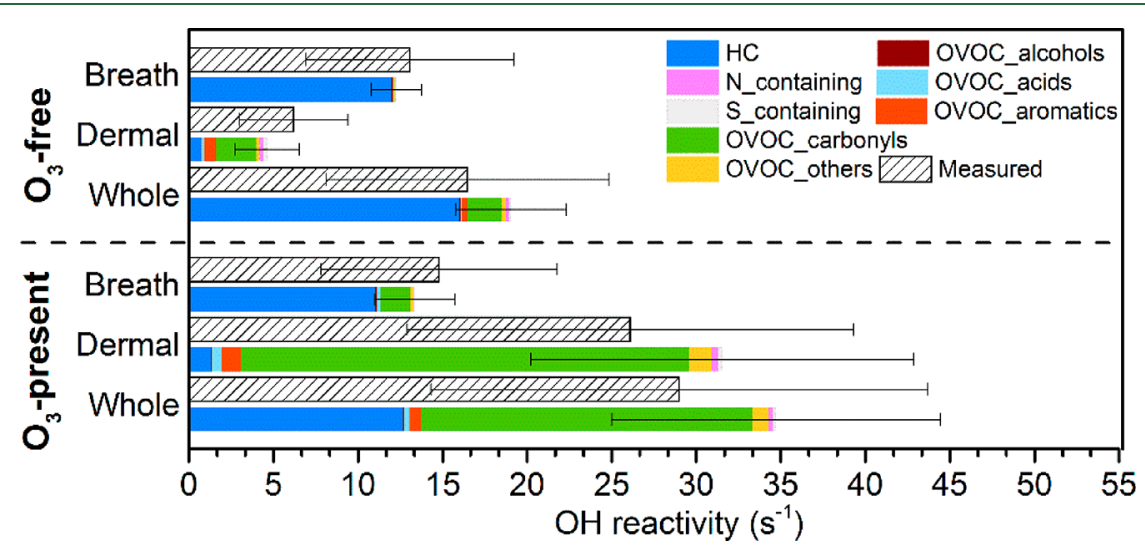

Figure 2. Measured and calculated $\mathrm{OH}$ reactivity of breath (Experiment 12), dermal (Experiment 13), and corresponding whole-body emissions (Experiment 10) under ozone-free and ozone-present conditions. Error bars represent the total uncertainty of the measured and calculated OH reactivity.

chamber $\left(16 \mathrm{~s}^{-1}\right.$ under the ozone-free condition and $33 \mathrm{~s}^{-1}$ under the ozone-present condition) were comparable to reactivities measured in megacities. ${ }^{50}$

As shown in Figure 1, under the ozone-free condition, hydrocarbons contributed the largest fraction $(81 \%)$ to the total $\mathrm{OH}$ reactivity (dominated by isoprene, 76\%, $12 \mathrm{~s}^{-1}$ ), followed by carbonyls (14\%). Although more than 70 species were considered in the calculation, the top 10 species accounted for $90 \%$ of the total $\mathrm{OH}$ reactivity (Table 2). Besides isoprene, the reactivity of the other nine species individually was less than $1 \mathrm{~s}^{-1}$. In contrast, after ozone was introduced into the chamber, the total $\mathrm{OH}$ reactivity doubled compared to that of the ozone-free condition. Carbonyl compounds constituted the largest fraction $\left(57 \%, 19 \mathrm{~s}^{-1}\right)$. The $\mathrm{OH}$ reactivity of hydrocarbons showed a small decrease when ozone was present, while the $\mathrm{OH}$ reactivity of OVOCs (except for alcohols) increased. In particular, the reactivity attributed to carbonyl compounds increased by almost an order of magnitude from $2 \mathrm{~s}^{-1}$ without ozone to $19 \mathrm{~s}^{-1}$ with ozone present. $6 \mathrm{MHO}$ alone accounted for $28 \%$ of the total reactivity under the ozone-present condition, which is comparable with the fractional contribution by isoprene (33\%). This occurred because of their abundance and fast reaction rate constants with $\mathrm{OH}$ radicals $\left(1.0 \times 10^{-10} \mathrm{~cm}^{3}\right.$ molecules $^{-1} \mathrm{~s}^{-1}$ for isoprene and $1.57 \times 10^{-10} \mathrm{~cm}^{3}$ molecules $^{-1} \mathrm{~s}^{-1}$ for $6 \mathrm{MHO}) .^{51,52}$ Isoprene is one of the most abundant VOCs observed in human breath. ${ }^{53} 6 \mathrm{MHO}$ is a major product of the reaction of ozone with squalene, one of the main components of skin lipids. ${ }^{15}$ It should be noted that acetone was found to be much more abundant than isoprene, with and without ozone. It is not only a major breath compound ${ }^{53}$ but also a squalene-ozone reaction product. ${ }^{15}$ However, due to its much smaller rate constant with the $\mathrm{OH}$ radical at $1.8 \times 10^{-13} \mathrm{~cm}^{3}$ molecules ${ }^{-1} \mathrm{~s}^{-1,54}$ its contribution to the total $\mathrm{OH}$ reactivity is relatively small $\left(<0.15 \mathrm{~s}^{-1}\right)$.

The reported $\mathrm{OH}$ reactivities of $16 \mathrm{~s}^{-1}$ under ozone-free and $33 \mathrm{~s}^{-1}$ under ozone-present conditions with four seated people inside the chamber (temperature range: $23-30{ }^{\circ} \mathrm{C}$ ), gave reactivities of 4.0 and $8.3 \mathrm{~s}^{-1}$ per person, respectively. No other direct indoor $\mathrm{OH}$ reactivity measurement results are available for comparison. However, as no significant missing reactivity was observed, we can compare our results to previous studies that reported calculated $\mathrm{OH}$ reactivity. For studies that reported concentrations of gas-phase species, the $\mathrm{OH}$ reactivity can be estimated using eq 1 . At an identical occupancy, the mixing ratios of indoor gas-phase species are impacted by the room volume, the ACR, and the surface removal rate. A bigger room volume and larger ACR lead to more dilution, which results in lower mixing ratios. In order to compare our results with those of other studies, we adjusted the estimated perperson $\mathrm{OH}$ reactivity in other studies for the differences in room volume and ACR between those studies and our data. The surface removal of a compound can be ignored if it reaches a steady state. Since the major compounds (isoprene and $6 \mathrm{MHO}$ ) contributing to the $\mathrm{OH}$ reactivity could quickly reach a steady state, the surface removal was not considered. Details of the adjustment method are given in the SI.

Table 3 compares the $\mathrm{OH}$ reactivity per person $\left(\mathrm{s}^{-1} \mathrm{p}^{-1}\right)$ of this study with those estimated for other human occupied indoor environments. The adjusted values for $\mathrm{OH}$ reactivity 

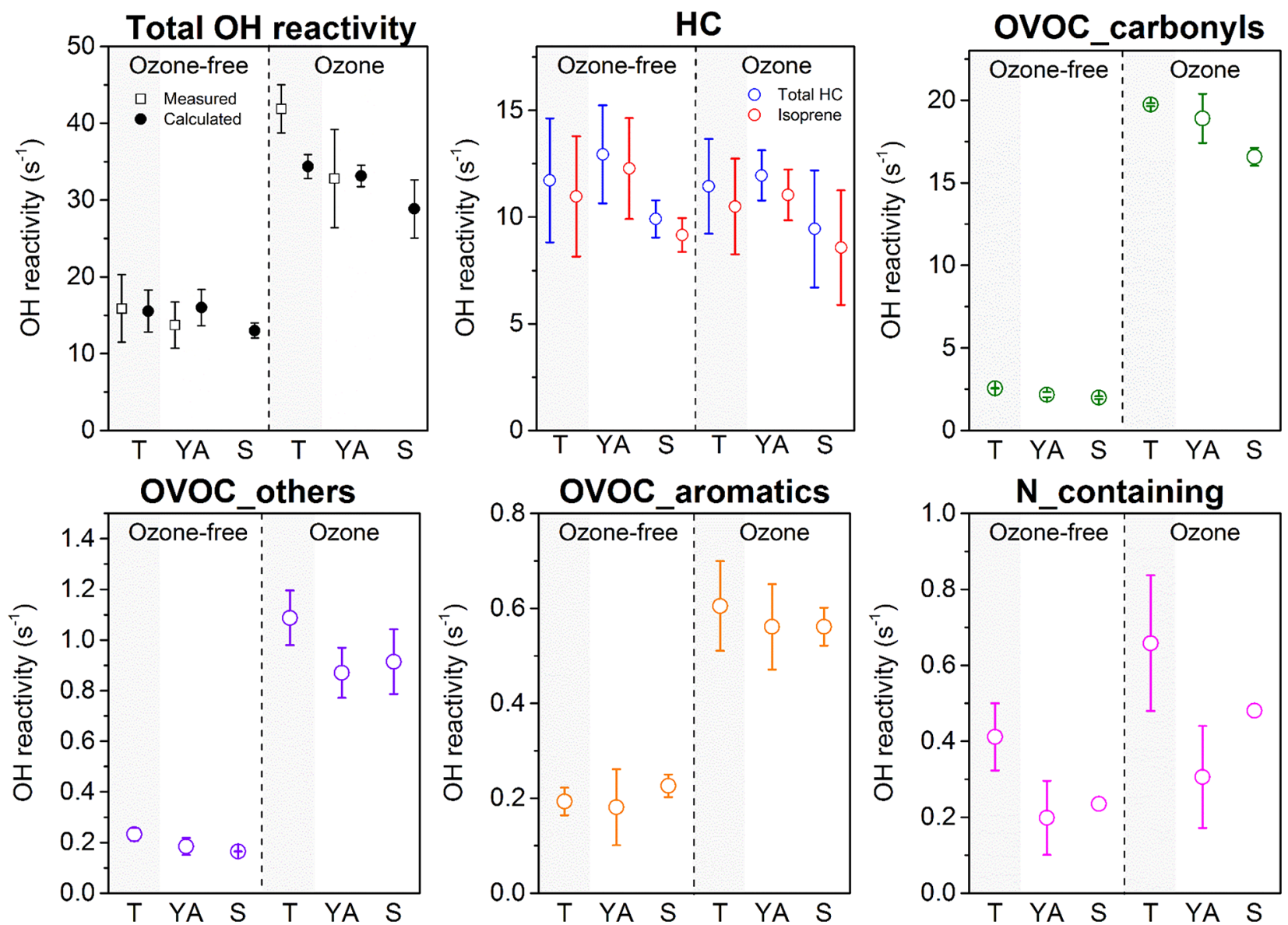

Figure 3. Total calculated and measured $\mathrm{OH}$ reactivity and the calculated $\mathrm{OH}$ reactivity for five chemical subgroups (those making the greatest contributions) for whole-body emissions from teenagers ( $\mathrm{T}, n=2)$, young adults (YA, $n=4)$, and seniors $(\mathrm{S}, n=2)$. Error bars refer to the standard deviations obtained from benchmark experiments in each age group. Since nitrogen containing species were dominated by ammonia (due to its high mixing ratios ${ }^{49}$ ) and the data were only available for one benchmark experiment, the variation (error bars) for the senior group (Experiment 25) could not be derived.

per person obtained in various occupied environments are comparable and within the range of our chamber results without and with ozone. In the museum gallery study, the total $\mathrm{OH}$ reactivity with a high occupant density was roughly $73 \%$ higher than the total $\mathrm{OH}$ reactivity with a low occupant density. This comparison underlines the significant effect of occupancy on the total $\mathrm{OH}$ reactivity in real-world indoor environments. The major species contributing to the $\mathrm{OH}$ reactivity in a classroom ${ }^{36}$ and a museum gallery ${ }^{40}$ were isoprene, monoterpenes, and $6 \mathrm{MHO}$. In a cinema, ${ }^{35}$ besides isoprene and monoterpenes, acetaldehyde, a common human bioeffluent compound, ${ }^{14}$ was the third compound contributing the most to the reactivity. The less $\mathrm{OH}$ reactivity contribution from $6 \mathrm{MHO}$ was probably caused by the lower level of ozone in winter leading to less skin-initiated oxidation products. ${ }^{35}$ The major species contributing to $\mathrm{OH}$ reactivity in our study (Table 2) agree well with those in other studies. However, when ozone was present in our chamber, carbonyls (not including $6 \mathrm{MHO}$ ) contributed to the reactivity more than monoterpenes (Table 2). This likely reflects the fact that the volunteers in our study did not use fragranced personal care products, which often contain monoterpenes (e.g., limonene). ${ }^{55}$ Overall, the comparable per-person $\mathrm{OH}$ reactivity and the similar major $\mathrm{OH}$ reactivity contributing species observed in various studies indicate the relative consistency of the $\mathrm{OH}$ reactivity budget of human emissions. The present study reveals the extent to which ozone in an occupied environment can amplify the total $\mathrm{OH}$ reactivity of human emissions.

3.2. Total $\mathrm{OH}$ Reactivity of Breath and Dermal Emissions. To better understand the relative contributions of breath and dermal emissions to the total whole-body $\mathrm{OH}$ reactivity, the results from Experiment 10 (whole-body, adult group A3) are shown in Figure 2 alongside the results from the separate breath and dermal emission experiments performed with the same group of volunteers. In general, the measured $\mathrm{OH}$ reactivity and the calculated $\mathrm{OH}$ reactivity were comparable. For breath-only emissions, the total $\mathrm{OH}$ reactivity without ozone $\left(13 \mathrm{~s}^{-1}\right)$ was similar to the total $\mathrm{OH}$ reactivity with ozone present $\left(14 \mathrm{~s}^{-1}\right)$. Hydrocarbon reactivity dominated the total reactivity under both ozone-free and ozone-present conditions. Although ozone had a negligible effect on the reactivity of breath-only emissions, the contribution of carbonyls showed an obvious increase under the ozone-present condition (Figure 2), accounting for 13\% (2 $\mathrm{s}^{-1}$ ) of the total calculated $\mathrm{OH}$ reactivity. It is likely due to ozone reacting with species in the air (e.g., isoprene and monoterpenes) as well as with a small amount of less volatile organic species (squalene, unsaturated fatty acids, etc.) remaining on the chamber surfaces. As for dermal emissions, the calculated reactivity was $5 \mathrm{~s}^{-1}$ under the ozone-free condition, which was close to the $\operatorname{LOD}\left(5 \mathrm{~s}^{-1}\right)$ of the 
measured reactivity. With ozone present, the $\mathrm{OH}$ reactivity increased significantly to $31 \mathrm{~s}^{-1}$, with carbonyl reactivity contributing the most $\left(84 \%, 26 \mathrm{~s}^{-1}\right)$. $6 \mathrm{MHO}$ alone accounted for $42 \%$ of the total $\left(13 \mathrm{~s}^{-1}\right)$. The sum of $\mathrm{OH}$ reactivity for breath and dermal emissions exceeded the whole-body $\mathrm{OH}$ reactivity, especially when ozone was present. The dermal-only experiment was performed with short clothing, while the other experiments were performed with long clothing. More skin area was exposed to ozone in the dermal-only experiment, leading to greater release of reactive species. In addition, the breath-only experiment was performed under a higher temperature and relative humidity, which made the comparison imperfect.

The top $10 \mathrm{OH}$ reactivity contributing species accounted for nearly all of the calculated total $\mathrm{OH}$ reactivity of breath emissions ( $99 \%$ at ozone-free and $94 \%$ at ozone-present conditions, Table S3). In contrast, the top $10 \mathrm{OH}$ reactivity contributing species accounted for 63\% $\left(3 \mathrm{~s}^{-1}\right)$ of the calculated total $\mathrm{OH}$ reactivity of dermal emissions under the ozone-free condition and for $75 \%\left(24 \mathrm{~s}^{-1}\right)$ under the ozonepresent condition (Table $\mathrm{S} 4$ ). The $\mathrm{OH}$ reactivity stemming from dermal emissions is more chemically diverse, especially under elevated ozone conditions. Similarly, for the whole-body emissions, the fraction that could not be explained by the top 10 contributing species increased from 10\% $\left(2 \mathrm{~s}^{-1}\right)$ without ozone to $18 \%\left(6 \mathrm{~s}^{-1}\right)$ with ozone (Table 2$)$, indicating that a diverse array of reactive species were released into the gas phase due to ozone-initiated oxidation. The top 10 species contributing to the whole-body $\mathrm{OH}$ reactivity (Table 2) could also be found in either the top 10 species of breath or dermal emissions (Tables S3 and S4). Taken together, the above results indicate that the reactivity of the whole-body emissions under the ozone-free condition was mostly determined by the reactivity of the breath emissions. A small additional carbonyl reactivity of the whole-body emissions was presumably attributable to the reactivity of dermal emissions, which was possibly induced by direct dermal emissions or exposure to ambient ozone prior to the experiments. The large increase in $\mathrm{OH}$ reactivity for whole-body emissions in the presence of ozone was attributable to the dramatic increase in products of reactions between ozone and dermal emissions (mainly carbonyls).

With ozone present, the $\mathrm{OH}$ reactivity budget was more broadly shared by a mix of carbonyls, especially aldehydes, due to dermal emissions (Figure 2 and Table 2). Mochalski et al. ${ }^{56}$ measured dermally emitted VOCs using GC-MS from 31 healthy volunteers and detected more aldehyde species compared with ketone species. Aldehydes and ketones with the same empirical formula are difficult to distinguish when using PTR-MS with $\mathrm{H}_{3} \mathrm{O}^{+}$as the primary reagent ion. According to Mochalski et al., ${ }^{56}$ carbonyls measured by PTR-MS in our study, especially mono carbonyls with a larger molecular weight (carbon number $>4$ ), are more likely to be aldehydes than ketones. Exceptions are certain ketones known as major skin lipid ozonolysis products (i.e., $6 \mathrm{MHO}$ and geranyl acetone). Aldehydes including 4-oxopantanal, nonanal, 1,4-butanedial, and nonenal ranked within the top 10 species contributing to the total reactivity under the ozone-present condition and have all been reported as ozone oxidation products from skin lipids. $37,38,57,58$

3.3. Total $\mathrm{OH}$ Reactivity for Volunteers of Different Ages. Similar to the results obtained with young adults (YA), the total $\mathrm{OH}$ reactivity for teenagers $(\mathrm{T})$ and seniors $(\mathrm{S})$ increased by a factor of $\sim 2$ when ozone was present in the chamber (Figure 3), compared to when it was absent. Consistently, the increase was mainly caused by increased carbonyls > OVOC others > aromatic OVOCs > nitrogen containing species. The contribution from alcohol, acids, and sulfur containing species were not shown in the plot, since they contributed negligible fractions to the total reactivity (below 0.2 and $0.5 \mathrm{~s}^{-1}$ under ozone-free and ozone-present conditions, respectively). The measured $\mathrm{OH}$ reactivity was generally in good agreement with the calculated reactivity for teenagers when ozone was absent. However, a higher $\mathrm{OH}$ reactivity was measured $\left(42 \pm 3 \mathrm{~s}^{-1}\right)$ compared to the calculated $\mathrm{OH}$ reactivity $\left(34 \pm 2 \mathrm{~s}^{-1}\right)$ for teenagers when ozone was present. Since this difference (missing reactivity of $8 \mathrm{~s}^{-1}, 19 \%$ ) was within the uncertainty of the measured reactivity (49\%), we cannot confidently interpret whether or not it was indicative of unmeasured species in this case.

Skin lipid emission rates tend to decrease with age, ${ }^{59}$ which may lead to less ozone-initiated chemistry on the skin and lower $\mathrm{OH}$ reactivity from dermal emissions in the presence of ozone among older individuals. Figure 3 shows that young adults and teenagers had similar calculated total $\mathrm{OH}$ reactivities when ozone was present $\left(33 \pm 1 \mathrm{~s}^{-1}\right.$ for YA, 34 $\pm 2 \mathrm{~s}^{-1}$ for $\mathrm{T}$ ), while the senior group showed a slightly lower reactivity $\left(29 \pm 4 \mathrm{~s}^{-1}\right)$. A similar pattern was observed for the $\mathrm{OH}$ reactivity contribution from carbonyls (Figure 3 ). This trend of decreasing $\mathrm{OH}$ reactivity from carbonyls in the presence of ozone with increasing age appears to support the view that less skin lipids are generated with increasing age. Another major contributor to the total reactivity is isoprene from exhaled breath, as discussed previously. The $\mathrm{OH}$ reactivity from isoprene was comparable under ozone-free and ozone-present conditions for all groups. As shown in Figure 3, seniors had a slightly lower reactivity attributable to isoprene compared to young adults and teenagers. This is in agreement with Kushch et al., ${ }^{60}$ who found isoprene levels in breath to decrease with age for men above 20 years. In contrary, other studies have found that younger children (ages 7-13) and young people in general (age below 30) emit less isoprene than elderly people. ${ }^{6,62}$ Besides age and sex, isoprene in breath was found to be related to physiological parameters like respiratory rate or cardiac output. ${ }^{63,64}$ The large error bars for isoprene reactivity indicate large variations even for the same group of people (Figure 3). The level of isoprene was likely influenced by multiple factors. In summary, due to the mixed gender character of the groups and the limited number of volunteers in the teenager and senior groups, it is not possible to discern a potential dependency of $\mathrm{OH}$ reactivity on age under ozone-free conditions.

In the absence of ozone, the top 10 species were similar among the age groups, together accounting for roughly $90 \%$ of the total $\mathrm{OH}$ reactivity (Figure S2a). Interestingly, nonenal was ranked within the top 10 species only for seniors; 2 -nonenal is found to be involved in aging-related body odor change. ${ }^{65}$ The sum of the top 10 species for each age group accounted for a smaller fraction of the total $\mathrm{OH}$ reactivity when ozone was present $(79 \%$ for teenagers, $83 \%$ young adults, and $79 \%$ for seniors, Figure S2b) than when ozone was absent. Many of the top species under ozone-free conditions were also among the top 10 consumers of $\mathrm{OH}$ in the presence of ozone. However, $6 \mathrm{MHO}$ rose to the second spot in the top 10 list. Two chemicals that were not in the top 10 when ozone was absent (4OPA and nonanal), were the third and fourth ranked sinks 
for $\mathrm{OH}$ in the presence of ozone in each age group. Although the amount of skin lipids per unit area decreases with age, the proportion of different skin lipid constituents remains similar regardless of age. ${ }^{59}$ Consistent with this, in the top 10 lists, the carbonyl species derived from ozone oxidation of skin lipids were similar across the three age groups (Figure S2).

3.4. Limitations and Implications of the Study. When ozone reacts with squalene, $6 \mathrm{MHO}$ and geranyl acetone are generated as primary products in roughly equal amounts (see Figure 1 in Wisthaler and Weschler ${ }^{37}$ ). These compounds are also generated by secondary reactions between ozone and other primary products of ozone/squalene chemistry. ${ }^{37}$ In the present study, the measured mixing ratios of geranyl acetone were much smaller, relative to the concentration of $6 \mathrm{MHO}$, than that measured in a simulated office ${ }^{37}$ or that measured in the present chamber ${ }^{66}$ under similar conditions. Geranyl acetone has a lower vapor pressure and larger octanol/air partition coefficient $\left(K_{\mathrm{oa}}\right)$ than $6 \mathrm{MHO}$, and hence, it has a greater tendency to sorb to surfaces, including those that constitute the sampling train. The sampling train for this study consisted of the main inlet tubing, a three-way valve, and subflows to the instruments, which is longer and more complex than those used in the earlier studies. Furthermore, the FEP tubing used in this study has been reported to have a greater tendency to sorb gas-phase organics than the PFA tubing ${ }^{67,68}$ used by Salvador et al. ${ }^{66}$ We speculate that in our study a significant fraction of geranyl acetone sorbed to the sampling train and that some of the sorbed geranyl acetone subsequently reacted with ozone passing through the sampling lines, generating $6 \mathrm{MHO}$. The length of the sampling tubing for the instrument that measured total $\mathrm{OH}$ reactivity and the instruments that measured speciated gas-phase organics was similar. Hence, the measured total $\mathrm{OH}$ reactivity and calculated total $\mathrm{OH}$ reactivity would have been comparably impacted by such an artifact-the air that reached the instruments would have had lower geranyl acetone and higher $6 \mathrm{MHO}$ concentrations than the chamber air. To some extent, the loss of geranyl acetone during sampling would be partially compensated by the production of $6 \mathrm{MHO}$ that resulted from ozone reacting with sorbed geranyl acetone. Hence, the measured total $\mathrm{OH}$ reactivity is more reliable than the individual measured concentrations of 6-MHO and geranyl acetone. However, this compensation is not expected to be perfect, as the $\mathrm{OH}$ rate constant for geranyl acetone (two double bonds) is expected to be higher than that for $6 \mathrm{MHO}$ (one double bond). The net result is that the total $\mathrm{OH}$ reactivity and the fractional contribution of geranyl acetone may be higher, while the fractional contribution of $6 \mathrm{MHO}$ may be lower than what we have reported in this study under the ozone-present condition. This sampling artifact should not have a large impact on the comparisons shown in Table 3, since the results from other studies have been obtained under conditions with much lower indoor ozone concentrations. We expect the per-person $\mathrm{OH}$ reactivity in the other studies to be closer to those measured for the ozone-free condition in the current study, as indeed they are. Meanwhile, the artifacts from hydroperoxide decomposition catalyzed by any metal surface were considered negligible in this study (see details in the SI).

It is worth noting that the agreement between the measured and calculated reactivity is a sensitive test of budget completeness for those organic compounds that have a higher $\mathrm{OH}$ reactivity. This method is however insensitive to the presence of unreactive species and blind to chemically inert species.

Ozone was the variable we deliberately changed during each experiment. However, the light lunch may be an unintended variable; subsequent changes in metabolism may slightly alter human breath and skin emissions, as suggested by Li et al. ${ }^{49}$ in the case of $\mathrm{NH}_{3}$. The reactivity with ozone present is highly driven by isoprene and $6 \mathrm{MHO}$. Isoprene, as an endogenous breath compound, would be more impacted by metabolism. However, exhaled isoprene levels can be affected by a number of variables, as mentioned in Section 3.3. Further experiments are needed to better define the influence of food intake on isoprene levels. Another limitation is the small number of subjects constituting the teenager and senior groups; this limited the power of statistical comparisons among the age groups.

Measuring the total $\mathrm{OH}$ reactivity is a novel method that supplements specific analytical methods used to measure individual species. This study demonstrates the application and feasibility of $\mathrm{OH}$ reactivity measurement in indoor environments. Although no significant unattributed reactivity was observed with and without ozone, differences were observed in the contributions of various chemical species. This study focused on human emissions in the absence of personal care products; further studies are needed to quantify the effect of such products (e.g., fragrances or deodorants) on $\mathrm{OH}$ reactivity. Meanwhile, during periods of lower traffic intensity (e.g., weekends or holiday periods or lockdowns), lower NOx emissions from vehicles may result in elevated ozone concentrations, especially in cities. ${ }^{69,70}$ This can lead to higher indoor reactivity and potentially to increased exposure to reaction products derived from occupant generated compounds.

\section{ASSOCIATED CONTENT}

\section{Supporting Information}

The Supporting Information is available free of charge at https://pubs.acs.org/doi/10.1021/acs.est.0c04206.

Discussions of comparative reactivity method operating procedures, interference and corrections of $\mathrm{OH}$ reactivity data analysis, calculations of precision and total uncertainty of CRM, empty-chamber background, definition of steady-state condition, adjustment method applied for $\mathrm{OH}$ reactivity per person comparison, and potential artifacts from decomposition of hydroperoxides, tables of uncertainties in the CRM, list of compounds used in calculating the estimated $\mathrm{OH}$ reactivity, and top 10 species contributing to the calculated $\mathrm{OH}$ reactivity of breath and dermal emissions, and figures of calculated and measured $\mathrm{OH}$ reactivity during ozone-free and ozone-present steady-state conditions of the benchmark experiments and top 10 species contributing to the total $\mathrm{OH}$ reactivity for teenagers, young adults and seniors (PDF)

\section{AUTHOR INFORMATION}

\section{Corresponding Author}

Nijing Wang - Max Planck Institute for Chemistry, Mainz 55128, Germany; 이이이.org/0000-0003-3197-8151; Email: nijing.wang@mpic.de 


\section{Authors}

Nora Zannoni - Max Planck Institute for Chemistry, Mainz 55128, Germany

Lisa Ernle - Max Planck Institute for Chemistry, Mainz 55128, Germany

Gabriel Bekö - International Centre for Indoor Environment and Energy, Department of Civil Engineering, Technical University of Denmark, Lyngby 2800, Denmark; (1) orcid.org/0000-0001-6107-8336

Pawel Wargocki - International Centre for Indoor Environment and Energy, Department of Civil Engineering, Technical University of Denmark, Lyngby 2800, Denmark

Mengze Li - Max Planck Institute for Chemistry, Mainz 55128, Germany; 이이이.org/0000-0003-0620-6301

Charles J. Weschler - International Centre for Indoor Environment and Energy, Department of Civil Engineering, Technical University of Denmark, Lyngby 2800, Denmark; Environmental and Occupational Health Sciences Institute, Rutgers University, Piscataway, New Jersey 08854, United States; (1) orcid.org/0000-0002-9097-5850

Jonathan Williams - Max Planck Institute for Chemistry, Mainz 55128, Germany; The Cyprus Institute, Nicosia 2121, Cyprus; (1) orcid.org/0000-0001-9421-1703

Complete contact information is available at: https://pubs.acs.org/10.1021/acs.est.0c04206

\section{Notes}

The authors declare no competing financial interest.

\section{ACKNOWLEDGMENTS}

This study was funded by the Alfred P. Sloan Foundation (Grant Number G-2018-11233). The authors would like to thank Dr. Sarka Langer for the support of $\mathrm{NO} / \mathrm{NO}_{x}$ analyzer. The authors appreciate the participation of all volunteers.

\section{REFERENCES}

(1) Brasche, S.; Bischof, W. Daily time spent indoors in German homes - Baseline data for the assessment of indoor exposure of German occupants. Int. J. Hyg. Environ. Health 2005, 208 (4), 247253.

(2) Leech, J. A.; Nelson, W. C.; Burnett, R. T.; Aaron, S.; Raizenne, M. E. It's about time: A comparison of Canadian and American timeactivity patterns. J. Exposure Sci. Environ. Epidemiol. 2002, 12 (6), 427-432.

(3) Moya, J.; Phillips, L.; Schuda, L.; Wood, P.; Diaz, A.; Lee, R.; Clickner, R.; Birch, R.; Adjei, N.; Blood, P. Exposure Factors Handbook: 2011 Edition; US Environmental Protection Agency: Washington, DC, 2011.

(4) Duan, X.; Zhao, X.; Wang, B.; Chen, Y.; Cao, S. Highlights of the Chinese exposure factors handbook; Academic Press, 2015.

(5) Klepeis, N. E.; Nelson, W. C.; Ott, W. R.; Robinson, J. P.; Tsang, A. M.; Switzer, P.; Behar, J. V.; Hern, S. C.; Engelmann, W. H. The National Human Activity Pattern Survey (NHAPS): a resource for assessing exposure to environmental pollutants. J. Exposure Sci. Environ. Epidemiol. 2001, 11 (3), 231-252.

(6) Salthammer, T.; Zhang, Y.; Mo, J.; Koch, H. M.; Weschler, C. J. Assessing Human Exposure to Organic Pollutants in the Indoor Environment. Angew. Chem., Int. Ed. 2018, 57 (38), 12228-12263.

(7) Bernstein, J. A.; Alexis, N.; Bacchus, H.; Bernstein, I. L.; Fritz, P.; Horner, E.; Li, N.; Mason, S.; Nel, A.; Oullette, J.; et al. The health effects of nonindustrial indoor air pollution. J. Allergy Clin. Immunol. 2008, 121 (3), 585-591.

(8) Levin, H. Building materials and indoor air quality. Occup. Med. 1989, 4 (4), 667-693.
(9) Hodgson, A. T.; Beal, D.; Mcllvaine, J. E. R. Sources of formaldehyde, other aldehydes and terpenes in a new manufactured house. Indoor Air 2002, 12 (4), 235-242.

(10) Weschler, C. J. Changes in indoor pollutants since the 1950s. Atmos. Environ. 2009, 43 (1), 153-169.

(11) Nazaroff, W. W.; Weschler, C. J. Cleaning products and air fresheners: exposure to primary and secondary air pollutants. Atmos. Environ. 2004, 38 (18), 2841-2865.

(12) Rudel, R. A.; Camann, D. E.; Spengler, J. D.; Korn, L. R.; Brody, J. G. Phthalates, Alkylphenols, Pesticides, Polybrominated Diphenyl Ethers, and Other Endocrine-Disrupting Compounds in Indoor Air and Dust. Environ. Sci. Technol. 2003, 37 (20), 45434553.

(13) Hodgson, A. T.; Wooley, J. D.; Daisey, J. M. Emissions of volatile organic compounds from new carpets measured in a largescale environmental chamber. Air Waste 1993, 43 (3), 316-324.

(14) de Lacy Costello, B.; Amann, A.; Al-Kateb, H.; Flynn, C.; Filipiak, W.; Khalid, T.; Osborne, D.; Ratcliffe, N. M. A review of the volatiles from the healthy human body. J. Breath Res. 2014, 8 (1), 014001 .

(15) Petrick, L.; Dubowski, Y. Heterogeneous oxidation of squalene film by ozone under various indoor conditions. Indoor Air 2009, 19 (5), 381-91.

(16) Young, C. J.; Zhou, S.; Siegel, J. A.; Kahan, T. F. Illuminating the dark side of indoor oxidants. Environ. Sci. Process Impacts 2019, 21 (8), 1229-1239.

(17) Weschler, C. J. Ozone in indoor environments: concentration and chemistry. Indoor air 2000, 10 (4), 269-288.

(18) Abbatt, J. P. D.; Wang, C. The atmospheric chemistry of indoor environments. Environ. Sci. Process Impacts 2020, 22 (1), 25-48.

(19) Weschler, C. J.; Carslaw, N. Indoor Chemistry. Environ. Sci. Technol. 2018, 52 (5), 2419-2428.

(20) Weschler, C. J.; Shields, H. C. Production of the hydroxyl radical in indoor air. Environ. Sci. Technol. 1996, 30 (11), 3250-3258.

(21) Weschler, C. J.; Shields, H. C. Measurements of the hydroxyl radical in a manipulated but realistic indoor environment. Environ. Sci. Technol. 1997, 31 (12), 3719-3722.

(22) White, I. R.; Martin, D.; Muñoz, M. P.; Petersson, F. K.; Henshaw, S. J.; Nickless, G.; Lloyd-Jones, G. C.; Clemitshaw, K. C.; Shallcross, D. E. Use of Reactive Tracers To Determine Ambient OH Radical Concentrations: Application within the Indoor Environment. Environ. Sci. Technol. 2010, 44 (16), 6269-6274.

(23) Gómez Alvarez, E.; Amedro, D.; Afif, C.; Gligorovski, S.; Schoemaecker, C.; Fittschen, C.; Doussin, J.-F.; Wortham, H. Unexpectedly high indoor hydroxyl radical concentrations associated with nitrous acid. Proc. Natl. Acad. Sci. U. S. A. 2013, 110 (33), 13294.

(24) Carslaw, N.; Fletcher, L.; Heard, D.; Ingham, T.; Walker, H. Significant $\mathrm{OH}$ production under surface cleaning and air cleaning conditions: Impact on indoor air quality. Indoor Air 2017, 27 (6), $1091-1100$

(25) Yang, Y.; Shao, M.; Keßel, S.; Li, Y.; Lu, K.; Lu, S.; Williams, J.; Zhang, Y.; Zeng, L.; Nölscher, A. C.; Wu, Y.; Wang, X.; Zheng, J. How the $\mathrm{OH}$ reactivity affects the ozone production efficiency: case studies in Beijing and Heshan, China. Atmos. Chem. Phys. 2017, 17 (11), $7127-7142$.

(26) Nölscher, A. C.; Yanez-Serrano, A. M.; Wolff, S.; de Araujo, A. C.; Lavric, J. V.; Kesselmeier, J.; Williams, J. Unexpected seasonality in quantity and composition of Amazon rainforest air reactivity. Nat. Commun. 2016, 7, 10383.

(27) Di Carlo, P.; Brune, W. H.; Martinez, M.; Harder, H.; Lesher, R.; Ren, X.; Thornberry, T.; Carroll, M. A.; Young, V.; Shepson, P. B.; Riemer, D.; Apel, E.; Campbell, C. Missing OH Reactivity in a Forest: Evidence for Unknown Reactive Biogenic VOCs. Science 2004, 304 (5671), 722.

(28) Zannoni, N.; Gros, V.; Sarda Esteve, R.; Kalogridis, C.; Michoud, V.; Dusanter, S.; Sauvage, S.; Locoge, N.; Colomb, A.; Bonsang, B. Summertime $\mathrm{OH}$ reactivity from a receptor coastal site in the Mediterranean Basin. Atmos. Chem. Phys. 2017, 17 (20), 1264512658 . 
(29) Sinha, V.; Williams, J.; Crowley, J.; Lelieveld, J. The Comparative Reactivity Method-a new tool to measure total $\mathrm{OH}$ Reactivity in ambient air. Atmos. Chem. Phys. 2008, 8 (8), 2213-2227.

(30) Pfannerstill, E. Y.; Wang, N.; Edtbauer, A.; Bourtsoukidis, E.; Crowley, J. N.; Dienhart, D.; Eger, P. G.; Ernle, L.; Fischer, H.; Hottmann, B.; Paris, J.-D.; Stönner, C.; Tadic, I.; Walter, D.; Lelieveld, J.; Williams, J. Shipborne measurements of total $\mathrm{OH}$ reactivity around the Arabian Peninsula and its role in ozone chemistry. Atmos. Chem. Phys. 2019, 19 (17), 11501-11523.

(31) Zannoni, N.; Gros, V.; Lanza, M.; Sarda, R.; Bonsang, B.; Kalogridis, C.; Preunkert, S.; Legrand, M.; Jambert, C.; Boissard, C.; Lathiere, J. OH reactivity and concentrations of biogenic volatile organic compounds in a Mediterranean forest of downy oak trees. Atmos. Chem. Phys. 2016, 16 (3), 1619-1636.

(32) Williams, J.; Keßel, S. U.; Nölscher, A. C.; Yang, Y.; Lee, Y.; Yáñez-Serrano, A. M.; Wolff, S.; Kesselmeier, J.; Klüpfel, T.; Lelieveld, J.; Shao, M. Opposite OH reactivity and ozone cycles in the Amazon rainforest and megacity Beijing: Subversion of biospheric oxidant control by anthropogenic emissions. Atmos. Environ. 2016, 125, 112118.

(33) Fuchs, H.; Novelli, A.; Rolletter, M.; Hofzumahaus, A.; Pfannerstill, E. Y.; Kessel, S.; Edtbauer, A.; Williams, J.; Michoud, V.; Dusanter, S.; Locoge, N.; Zannoni, N.; Gros, V.; Truong, F.; SardaEsteve, R.; Cryer, D. R.; Brumby, C. A.; Whalley, L. K.; Stone, D.; Seakins, P. W.; Heard, D. E.; Schoemaecker, C.; Blocquet, M.; Coudert, S.; Batut, S.; Fittschen, C.; Thames, A. B.; Brune, W. H.; Ernest, C.; Harder, H.; Muller, J. B. A.; Elste, T.; Kubistin, D.; Andres, S.; Bohn, B.; Hohaus, T.; Holland, F.; Li, X.; Rohrer, F.; KiendlerScharr, A.; Tillmann, R.; Wegener, R.; Yu, Z.; Zou, Q.; Wahner, A. Comparison of $\mathrm{OH}$ reactivity measurements in the atmospheric simulation chamber SAPHIR. Atmos. Meas. Tech. 2017, 10 (10), 4023-4053.

(34) Pagonis, D.; Price, D. J.; Algrim, L. B.; Day, D. A.; Handschy, A. V.; Stark, H.; Miller, S. L.; de Gouw, J.; Jimenez, J. L.; Ziemann, P. J. Time-Resolved Measurements of Indoor Chemical Emissions, Deposition, and Reactions in a University Art Museum. Environ. Sci. Technol. 2019, 53 (9), 4794-4802.

(35) Stönner, C.; Edtbauer, A.; Williams, J. Real-world volatile organic compound emission rates from seated adults and children for use in indoor air studies. Indoor Air 2018, 28 (1), 164-172.

(36) Tang, X.; Misztal, P. K.; Nazaroff, W. W.; Goldstein, A. H. Volatile Organic Compound Emissions from Humans Indoors. Environ. Sci. Technol. 2016, 50 (23), 12686-12694.

(37) Wisthaler, A.; Weschler, C. J. Reactions of ozone with human skin lipids: sources of carbonyls, dicarbonyls, and hydroxycarbonyls in indoor air. Proc. Natl. Acad. Sci. U. S. A. 2010, 107 (15), 6568-6575.

(38) Weschler, C. J.; Wisthaler, A.; Cowlin, S.; Tamás, G.; StrømTejsen, P.; Hodgson, A. T.; Destaillats, H.; Herrington, J.; Zhang, J.; Nazaroff, W. W. Ozone-initiated chemistry in an occupied simulated aircraft cabin. Environ. Sci. Technol. 2007, 41 (17), 6177-6184.

(39) Liu, S.; Li, R.; Wild, R. J.; Warneke, C.; de Gouw, J. A.; Brown, S. S.; Miller, S. L.; Luongo, J. C.; Jimenez, J. L.; Ziemann, P. J. Contribution of human-related sources to indoor volatile organic compounds in a university classroom. Indoor Air 2016, 26 (6), 925938.

(40) Price, D. J.; Day, D. A.; Pagonis, D.; Stark, H.; Algrim, L. B.; Handschy, A. V.; Liu, S.; Krechmer, J. E.; Miller, S. L.; Hunter, J. F.; de Gouw, J. A.; Ziemann, P. J.; Jimenez, J. L. Budgets of Organic Carbon Composition and Oxidation in Indoor Air. Environ. Sci. Technol. 2019, 53 (22), 13053-13063.

(41) Weschler, C. J. Ozone's Impact on Public Health: Contributions from Indoor Exposures to Ozone and Products of Ozone-Initiated Chemistry. Environ. Health Perspect. 2006, 114 (10), $1489-1496$.

(42) Bekö, G.; Wargocki, P.; Wang, N.; Li, M.; Weschler, C. J.; Morrison, G.; Langer, S.; Ernle, L.; Licina, D.; Yang, S.; Zannoni, N.; Williams, J. The Indoor Chemical Human Emissions and Reactivity project (ICHEAR): Overview of experimental methodology and preliminary results. Indoor Air 2020, 30, 1213.
(43) Michoud, V.; Hansen, R. F.; Locoge, N.; Stevens, P. S.; Dusanter, S. Detailed characterizations of the new Mines Douai comparative reactivity method instrument via laboratory experiments and modeling. Atmos. Meas. Tech. 2015, 8 (8), 3537-3553.

(44) Lindinger, W.; Hansel, A.; Jordan, A. On-line monitoring of volatile organic compounds at pptv levels by means of protontransfer-reaction mass spectrometry (PTR-MS) medical applications, food control and environmental research. Int. J. Mass Spectrom. Ion Processes 1998, 173 (3), 191-241.

(45) Zhao, J.; Zhang, R. Proton transfer reaction rate constants between hydronium ion $(\mathrm{H} 3 \mathrm{O}+)$ and volatile organic compounds. Atmos. Environ. 2004, 38 (14), 2177-2185.

(46) Amelynck, C.; Schoon, N.; Kuppens, T.; Bultinck, P.; Arijs, E. A selected ion flow tube study of the reactions of $\mathrm{H} 3 \mathrm{O}+, \mathrm{NO}+$ and $\mathrm{O} 2+$ with some oxygenated biogenic volatile organic compounds. Int. J. Mass Spectrom. 2005, 247 (1-3), 1-9.

(47) Ruzsanyi, V.; Fischer, L.; Herbig, J.; Ager, C.; Amann, A. Multicapillary-column proton-transfer-reaction time-of-flight mass spectrometry. J. Chromatogr A 2013, 1316, 112-8.

(48) Bourtsoukidis, E.; Helleis, F.; Tomsche, L.; Fischer, H.; Hofmann, R.; Lelieveld, J.; Williams, J. An aircraft gas chromatographmass spectrometer System for Organic Fast Identification Analysis (SOFIA): design, performance and a case study of Asian monsoon pollution outflow. Atmos. Meas. Tech. 2017, 10 (12), 5089-5105.

(49) Li, M.; Weschler, C. J.; Beko, G.; Wargocki, P.; Lucic, G.; Williams, J. Human ammonia emission rates under various indoor environmental conditions. Environ. Sci. Technol. 2020, 54 (9), 54195428.

(50) Yang, Y.; Shao, M.; Wang, X.; Nölscher, A. C.; Kessel, S.; Guenther, A.; Williams, J. Towards a quantitative understanding of total $\mathrm{OH}$ reactivity: A review. Atmos. Environ. 2016, 134, 147-161.

(51) Smith, A. M.; Rigler, E.; Kwok, E. S. C.; Atkinson, R. Kinetics and Products of the Gas-Phase Reactions of 6-Methyl-5-hepten-2-one and trans-Cinnamaldehyde with $\mathrm{OH}$ and NO3 Radicals and $\mathrm{O} 3$ at $296 \pm 2$ K. Environ. Sci. Technol. 1996, 30 (5), 1781-1785.

(52) Atkinson, R.; Arey, J. Atmospheric Degradation of Volatile Organic Compounds. Chem. Rev. 2003, 103 (12), 4605-4638.

(53) Fenske, J. D.; Paulson, S. E. Human breath emissions of VOCs. J. Air Waste Manage. Assoc. 1999, 49 (5), 594-8.

(54) Atkinson, R.; Baulch, D.; Cox, R.; Crowley, J.; Hampson, R.; Hynes, R.; Jenkin, M.; Rossi, M.; Troe, J. Evaluated kinetic and photochemical data for atmospheric chemistry: Volume I-gas phase reactions of Ox, HOx, NOx and SOx species. Atmos. Chem. Phys. 2004, 4 (6), 1461-1738.

(55) Steinemann, A. C.; MacGregor, I. C.; Gordon, S. M.; Gallagher, L. G.; Davis, A. L.; Ribeiro, D. S.; Wallace, L. A. Fragranced consumer products: Chemicals emitted, ingredients unlisted. Environmental Impact Assessment Review 2011, 31 (3), 328-333.

(56) Mochalski, P.; King, J.; Unterkofler, K.; Hinterhuber, H.; Amann, A. Emission rates of selected volatile organic compounds from skin of healthy volunteers. J. Chromatogr. B: Anal. Technol. Biomed. Life Sci. 2014, 959, 62-70.

(57) Weschler, C. J. Roles of the human occupant in indoor chemistry. Indoor Air 2016, 26 (1), 6-24.

(58) Wisthaler, A.; Tamás, G.; Wyon, D. P.; Strøm-Tejsen, P.; Space, D.; Beauchamp, J.; Hansel, A.; Märk, T. D.; Weschler, C. J. Products of ozone-initiated chemistry in a simulated aircraft environment. Environ. Sci. Technol. 2005, 39 (13), 4823-4832.

(59) Waller, J. M.; Maibach, H. I. Age and skin structure and function, a quantitative approach (II): protein, glycosaminoglycan, water, and lipid content and structure. Skin Research and Technology 2006, 12 (3), 145-154.

(60) Kushch, I.; Arendacka, B.; Stolc, S.; Mochalski, P.; Filipiak, W.; Schwarz, K.; Schwentner, L.; Schmid, A.; Dzien, A.; Lechleitner, M.; Witkovsky, V.; Miekisch, W.; Schubert, J.; Unterkofler, K.; Amann, A. Breath isoprene-aspects of normal physiology related to age, gender and cholesterol profile as determined in a proton transfer reaction mass spectrometry study. Clin. Chem. Lab. Med. 2008, 46 (7), 10111018. 
(61) Lechner, M.; Moser, B.; Niederseer, D.; Karlseder, A.; Holzknecht, B.; Fuchs, M.; Colvin, S.; Tilg, H.; Rieder, J. Gender and age specific differences in exhaled isoprene levels. Respir. Physiol. Neurobiol. 2006, 154 (3), 478-83.

(62) Smith, D.; Spaněl, P.; Enderby, B.; Lenney, W.; Turner, C.; Davies, S. J. Isoprene levels in the exhaled breath of 200 healthy pupils within the age range 7-18 years studied using SIFT-MS. J. Breath Res. 2010, 4 (1), 017101.

(63) Sukul, P.; Schubert, J. K.; Oertel, P.; Kamysek, S.; Taunk, K.; Trefz, P.; Miekisch, W. FEV manoeuvre induced changes in breath VOC compositions: an unconventional view on lung function tests. Sci. Rep. 2016, 6 (1), 28029.

(64) Schubert, R.; Schwoebel, H.; Mau-Moeller, A.; Behrens, M.; Fuchs, P.; Sklorz, M.; Schubert, J. K.; Bruhn, S.; Miekisch, W. Metabolic monitoring and assessment of anaerobic threshold by means of breath biomarkers. Metabolomics 2012, 8 (6), 1069-1080. (65) Haze, S.; Gozu, Y.; Nakamura, S.; Kohno, Y.; Sawano, K.; Ohta, H.; Yamazaki, K. 2-Nonenal newly found in human body odor tends to increase with aging. J. Invest. Dermatol. 2001, 116 (4), 520-4.

(66) Salvador, C. M.; Beko, G.; Weschler, C. J.; Morrison, G.; Le Breton, M.; Hallquist, M.; Ekberg, L.; Langer, S. Indoor ozone/ human chemistry and ventilation strategies. Indoor Air 2019, 29 (6), 913-925.

(67) Liu, X.; Deming, B.; Pagonis, D.; Day, D. A.; Palm, B. B.; Talukdar, R.; Roberts, J. M.; Veres, P. R.; Krechmer, J. E.; Thornton, J. A.; de Gouw, J. A.; Ziemann, P. J.; Jimenez, J. L. Effects of gas-wall interactions on measurements of semivolatile compounds and small polar molecules. Atmos. Meas. Tech. 2019, 12 (6), 3137-3149.

(68) Deming, B. L.; Pagonis, D.; Liu, X.; Day, D. A.; Talukdar, R.; Krechmer, J. E.; de Gouw, J. A.; Jimenez, J. L.; Ziemann, P. J. Measurements of delays of gas-phase compounds in a wide variety of tubing materials due to gas-wall interactions. Atmos. Meas. Tech. 2019, 12 (6), 3453-3461.

(69) Wang, L.; Li, M.; Yu, S.; Chen, X.; Li, Z.; Zhang, Y.; Jiang, L.; Xia, Y.; Li, J.; Liu, W.; Li, P.; Lichtfouse, E.; Rosenfeld, D.; Seinfeld, J. $\mathrm{H}$. Unexpected rise of ozone in urban and rural areas, and sulfur dioxide in rural areas during the coronavirus city lockdown in Hangzhou, China: implications for air quality. Environ. Chem. Lett. 2020, 18 (5), 1713.

(70) Sicard, P.; De Marco, A.; Agathokleous, E.; Feng, Z.; Xu, X.; Paoletti, E.; Rodriguez, J. J. D.; Calatayud, V. Amplified ozone pollution in cities during the COVID-19 lockdown. Sci. Total Environ. 2020, 735, 139542. 